\title{
ISOTOPE FRACTIONATION RELATED TO KIMBERLITE MAGMATISM AND DIAMOND FORMATION.
}

Galimov, E.M.

V.I. Verndskii Institute of Geochemistry and Analytical Chemistry, Academy of Sciences of the USSR, Kosygin str. 19, B-334 Moscow, USSR.

Experimental data on carbon isotope composition of diamond, carbonate component of kimberlite, graphite, and organic carbon related to kimberlite minerals obtained during study of diamond bearing sources of East Siberia and some other regions show that $\delta 13 \mathrm{C}$ values of different forms of carbon related to kimberlite magmatism vary widely: from-35 to $+35 \%$.

The median value of $\delta^{13} \mathrm{C}$-distribution for about 2000 diamonds studied in our laboratory is $-4.54 \%$. More than $90 \%$ of diamonds from kimberlites have $\delta 13 \mathrm{C}$ which fall into the narrow range: $+4 \%$ of this value. However the whole range of variation of carbon isotope composition of natural diamonds is from -34 to $+2.8 \%$. On the basis of analysis of more than 600 diamonds, containing mineral inclusions, it has been established, that diamonds of ultrabasic paragenesis have $\delta 13 \mathrm{C}$ values almost entirely within the narrow range of $813 \mathrm{C}$ variations: $-4.5+4$, whereas $\delta 13 \mathrm{C}$ of diamonds of the basic (eclogitic) paragenesis cover the whole range of the isotope variations for diamonds. When a diamond consists of several sequential generations of growth (coated diamonds, diamond-in-diamond), ${ }^{13} \mathrm{C}$ values of the early generation varies widely whereas the isotopic composition of the later is more uniform. The $\delta 13 \mathrm{C}-$ distribution for diamonds is specific for a particular occurrence (different kimberlite pipes, different regions etc.).

Carbonates of magmatic origin in kimberlites from pipe Udachnaya are characterized by $\delta 13 \mathrm{C}$ values similar to those for diamonds of the ultrabasic paragenesis from the same pipe. However some autholiths are extremely enriched in ${ }^{13} \mathrm{C}$ as high as +35\%. Organic compounds in kimberlites, including that occurring in fluid inclusions of magmatic minerals (olivin and pyrope) are depleted in ${ }^{13} \mathrm{C}$ down to-30\%.

One of the possible causes of the observed isotope variations is believed to be the incorporation of the crustal carbon into the mantle. However this idea is inconsistent with some of the regularities observed, e.c. existence of the isotope heterogeneity within the same crystal, difference between internal and external parts of coated diamonds, peculiarities of isotope distribution for diamonds from different kimberlite bodies and of different paragenesis. Also, the range of the isotope variations of magmatic carbon in kimberlites is comparable or even exceeds that of sedimentary carbon of the oceanic crust, including both of its carbonate and organic form. It is unlikely that the subducted carbon would retain the isotope heterogeneity in full scale. 
The alternative explanation of the isotope variations is based on the possibility of significant isotope fractionation in the mantle. Isotopic fractionation under equilibrium conditions at high temperature is small and may have been responsible for a maximum fractionation of $3-5 \%$., depending on temperature and composition of $\mathrm{C}-\mathrm{H}-\mathrm{O}$ system. However, even small isotope effects between two components may provide large isotopic fractionation, if these components have different distribution coefficients between phases of a system, and these phases may spatially be separated. This situation may occur if a reduced subasthenospheric fluid interacts with the relatively oxidized lithosphere. As fluid ascends isotope fractionation between reduced and oxidized carbon in conjugation with the Rayleigh distillation mechanism may result in high enrichment of the residual carbon of the fluid in the light isotope.

On other hand, the same process, supposed, which leads to the isotope fractionation of carbon in the fluid may bring about formation of a basic melt. This might explain why the isotopically light diamonds are associated with the basic assemblage of the mineral inclusions.

The oxidized lithosphere could appear not from the beginning of the Earth history. If the ancient mantle was completely reduced, the mechanism of the isotope fractionation could not operate and isotopically light diamonds could not occur at that time. Moreover, if appearance of the eclogite assemblage related to the same process, diamonds of eclogite paragenesis could not occur among the most ancient diamonds. In the extreme case, which cannot be ruled out, the ancient diamonds could be predominantly (if not entirely) of ultrabasic paragenesis while the younger diamonds are predominantly (if not entirely) of eclogitic paragenesis. The boundary between "the ancient" and "the younger" depends on the actual history of the evolution of the redox state of the mantle. It might be elucidated by the carbon isotope study of diamonds combined with geochronology study of their mineral inclusions.

The same approach may be applied to consideration of isotope fractionation related to the carbonate component. The $\delta 13 \mathrm{C}$-value of about $-5 \%$ is initial for the $\mathrm{CO} 2$ component of the mantle as well. Under high pressure mantle rocks contain $\mathrm{CO} 2$ in carbonate form. When the carbonate bearing rocks or melts get the shallower depths which correspond to the boundary of stability of carbonate (at the pressure less than $25 \mathrm{kbar}$ under $\mathrm{T}>1100{ }^{\circ} \mathrm{C}$ ) carbonate decomposes and $\mathrm{CO}_{2}-$ gas is released. Expansion of the gas must have brought

about propagation of a fracture, through which the fluidizing magma could rush to the surface. This process must also be resulted in adiabatic drop of temperature. When temperature decreases to about $700-8000^{\circ}$ carbonates again become stable and $\mathrm{CO}_{2}$ reacts with the silicates (even in a low pressure). Experimental study showed that reaction of $\mathrm{CO} 2$ with $\mathrm{CaO}$ was accompanied by kinetic isotope effect up to $10,5 \%$. With an isotope effect of this magnitude the Rayleigh distillation process may result in enrichment of the residual $\mathrm{CO}_{2}$ greater than $+40 \%$., when less than $1 \%$ of the $\mathrm{CO}_{2}$ remains unbound. 
Hence one can explain occurrence of the ${ }^{13} \mathrm{C}-e n r i c h e d$ calcite in kimberlite, in particular, in the form of autoliths. The mineralogical peculiarities of the latter, which are believed to indicate that they crystallized from a turbulent flow of a fluidizing magma, are in agreement with the mechanism of their enrichment in ${ }^{13} \mathrm{C}$ isotope suggested here.

The adiabatic cooling also provides a possible explanation for several other curious features of kimberlite magmatism. It is known that kimberlite magma, despite the fact that it moves rapidly from a high-temperature zone, is relatively cool. The walls of kimberlite pipes and xenolites do not bear any evidence of strong thermal alteration. Besides, since kimberlites are rich in a $\mathrm{CO}_{2}$-component, many believe that a kimberlite magma is essentially degassed during formation of a kimberlite pipe and consequently loses a large amount of $\mathrm{CO}_{2}$. However there exists an almost stoichiometric correspondence between $\mathrm{CO}_{2}$ and $\mathrm{CaO}$ content in different kimberlites, that indicates that kimberlite magma loses little (if any) its $\mathrm{CO}_{2}$ component. This is in agreement with the model suggested. 